\title{
BANK SAMPAH SEBAGAI ALTERNATIF STRATEGI PENGELOLAAN SAMPAH BERBASIS MASYARAKAT DI TASIKMALAYA \\ (Bank Sampah (Waste Banks) as an Alternative of Community-Based Waste Management Strategy in Tasikmalaya)
}

\author{
Donna Asteria $^{1^{*}}$ dan Heru Heruman ${ }^{2}$ \\ ${ }^{1}$ Departemen Ilmu Komunikasi Fakultas Ilmu Sosial dan Ilmu Politik Universitas Indonesia \\ Gedung Komunikasi, Kampus FISIP UI, Depok 16424. \\ ${ }^{2}$ Lembaga Studi Pemberdayaan Ekonomi Rakyat (LSPeR), \\ Jl. Dr. Moch. Hatta no. 260, Tasikmalaya 46131.
}

*Penulis korespondensi. Tel: 021-7866324. Email: donnaasteria@gmail.com.

Diterima: 25 Juni 2015

Disetujui: 1 September 2015

\begin{abstract}
Abstrak
Perubahan paradigma masyarakat mengenai sampah perlu dilakukan secara berkelanjutan. Edukasi kesadaraan dan keterampilan warga untuk pengelolaan sampah dengan penerapan prinsip reduce, reuse, recycle dan replant (4R) penting dalam penyelesaian masalah sampah melalui pengelolaan sampah sejak dari sumbernya. Bank sampah yang berbasiskan partisipasi warga perempuan merupakan modal sosial dalam pengelolaan sampah berbasis masyarakat. Bank sampah yang diintegrasikan dengan prinsip 4R dilaksanakan di Kampung Karangresik, Tasikmalaya, Indonesia. Kegiatan bank sampah merupakan konsep pengumpulan sampah kering dan dipilah serta memiliki manajemen layaknya perbankan tapi yang ditabung bukan uang melainkan sampah. Pemberdayaan warga melalui kegiatan penyuluhan, edukasi, pelatihan dengan metode partisipasi emansipatoris (interaksi dan komunikasi), serta dialog dengan warga di komunitas. Selain itu diperlukan dukungan kemitraan dengan membangun jejaring dan mekanisme kerja sama kelembagaan antara warga pengelola bank sampah dengan stakeholder terkait. Bank Sampah Pucuk Resik (BSPR) di Kampung Karangresik ini telah memberikan manfaat kepada warga, terutama manfaat langsung dengan berkurangnya timbulan sampah di komunitas, lingkungan menjadi lebih bersih dan asri, serta kemandirian warga secara ekonomi. Selain manfaat secara ekonomi, dimana dari tabungan sampah memperoleh uang untuk membayar listrik dan membeli sembako, juga terwujudnya kesehatan lingkungan, dengan kondisi komunitas yang lebih bersih, hijau, nyaman, dan sehat. Pengelolaan sampah terintegrasi dapat menstimulasi kreativitas dan inovasi dari masyarakat sehingga meningkatkan kesejahteraan warga.
\end{abstract}

Kata kunci: bank sampah, edukasi kesadaran lingkungan, kesehatan lingkungan, partisipasi warga perempuan, pengelolaan sampah berbasis masyarakat.

\begin{abstract}
Change of paradigm in community about the waste needs to be done with sustainable action. Education of awareness and skills of citizen for waste management with the application of the principle of reduce, reuse, recycle and replant (4R) is important in solving the waste problem through waste management from the source. Bank sampah (the waste bank) with participation of women in community are the social capital of community-based waste management. Bank sampah integrated with $4 R$ principles implemented in at Kampung Karangresik, Tasikmalaya, Indonesia. Activity of bank sampah is the concept of dry waste collection and sorting as well as having appropriate management of banking, not the money saved, but trash. Empowerment of citizens through counseling, education, training with the method of participationemancipatory (interaction and communication), as well as dialogue with the citizens in the community. Besides of that, the necessary of partnerships, networking and institutional cooperation mechanism between the citizens of the waste bank managers with local stakeholders. Bank Sampah Pucuk Resik (BSPR) in Kampung Karangresik provides benefits to citizens, especially the direct benefits with reduced waste generation in the community, the environment becomes more clean and beautiful, as well as the economic independence of citizens. In addition to economic benefits from saving litter, citizens earned money to pay for electricity and buy groceries, as well as the realization of environmental health with the condition of environment that is more clean, green, comfortable, and healthy. Integrated waste management can stimulate creativity and innovation so as to improve the welfare of the community.
\end{abstract}

Keywords: bank sampah (waste banks), environmental awareness education, environmental health, community-based waste management, participation of women. 


\section{PENDAHULUAN}

Edukasi masyarakat mengenai permasalahan lingkungan yang bersifat kompleks akibat timbulan sampah diperlukan untuk membentuk kesadaran masyarakat. Faktor penyebab kepedulian lingkungan didasari cara berpikir dan perilaku manusia. Partisipasi aktif warga menjadi hal yang penting untuk diidentifikasikan dalam aksi pengelolaan sampah. Upaya menjaga kelestarian lingkungan harus bermula dari diri individu dengan memulai dengan melakukan hal-hal kecil. Perubahan yang dilakukan kemudian dapat 'ditularkan' menjadi kebiasaan dalam keluarga ataupun masyarakat, sehingga terjadi perubahan besar. Menurut Singhirunnusorn dkk. (2012), perubahan cara berpikir masyarakat mengenai pengelolaan sampah rumah tangga untuk mengurangi sampah di sumber melalui partisipasi warga harus diintegrasikan ke dalam proyek bank sampah yang berbasis masyarakat.

Sesuai dengan filosofi mendasar mengenai pengelolaan sampah sesuai dengan ketetapan dalam Undang Undang Nomor 18 Tahun 2008 tentang Pengelolaan Sampah, kini perlu perubahan cara pandang masyarakat mengenai sampah dan cara memperlakukan atau mengelola sampah. Cara pandang masyarakat pada sampah seharusnya tidak lagi memandang sampah sebagai hasil buangan yang tidak berguna. Sampah seharusnya dipandang sebagai sesuatu yang mempunyai nilai guna dan manfaat. Dalam rangka melaksanakan Peraturan Pemerintah No. 81 Tahun 2012 tentang Pengelolaan Sampah Rumah Tangga dan Sampah Sejenis Sampah Rumah Tangga, maka praktek mengolah dan memanfaatkan sampah harus menjadi langkah nyata dalam mengelola sampah. Masyarakat harus meninggalkan cara lama yang hanya membuang sampah dengan mendidik dan membiasakan masyarakat memilah, memilih, dan menghargai sampah sekaligus mengembangkan ekonomi kerakyatan melalui pengembangan bank sampah (Tallei dkk., 2013). Hal ini khususnya dalam pengelolaan sampah rumah tangga berbasis komunitas dikarenakan sumber sampah domestik perlu dikelola secara mandiri (Riswan dkk, 2011).

Pengetahuan, sikap, dan keterampilan warga mengelola sampah rumah tangga untuk melakukan daur ulang juga menjadi hal penting dalam pengelolaan sampah (Akhtar dan Soetjipto, 2014). Pemilahan sampah rumah tangga yang termasuk kategori sampah organik dapat dijadikan kompos sedangkan sampah rumah tangga anargonik ditabungkan ke bank sampah untuk didaur ulang kembali dan dapat dijadikan bahan yang bernilai ekonomis (Jumar dkk. 2014). Adaptasi bank sampah pada setiap komunitas sangat ditentukan partisipasi warga yang juga akan menentukan keberlanjutan program bank sampah sehingga pengelolaan berbasis komunitas menjadi perlu diperhatikan (Kristina, 2014).

Pada dasarnya bank sampah merupakan konsep pengumpulan sampah kering dan dipilah serta memiliki manajemen layaknya perbankan, tetapi yang ditabung bukan uang melainkan sampah. Warga yang menabung (menyerahkan sampah) juga disebut nasabah dan memiliki buku tabungan serta dapat meminjam uang yang nantinya dikembalikan dengan sampah seharga uang yang dipinjam. Sampah yang ditabung akan ditimbang dan dihargai dengan sejumlah uang, kemudian akan dijual di pabrik yang sudah bekerja sama dengan bank sampah. Sementara plastik kemasan dapat dibeli oleh pengurus PKK setempat untuk didaur ulang menjadi barang-barang kerajinan (Anonim, 2012).

Pendekatan yang sesuai dengan konteks masyarakat dan kesesuaian kebutuhan masyarakat menjadi kunci dari perubahan. Sementara Purba dkk. (2014) menjelaskan bahwa pengembangan bank sampah ini juga akan membantu pemerintah lokal dalam pemberdayaan masyarakat untuk mengelola sampah berbasis komunitas secara bijak dan dapat mengurangi sampah yang diangkut ke Tempat Pembuangan Akhir (TPA). Inovasi pengolahan sampah dengan program bank sampah menjadi inovasi di tingkat akar rumput yang dapat meningkatkan pendapatan masyarakat miskin perkotaan (Winarso dan Larasati, 2011).

Penekanan pada kajian ini yang menjadi kebaruan dari kajian sebelumnya adalah pemberdayaan masyarakat berbasis komunitas yang lebih berperspektif gender. Peran warga perempuan penting diperhatikan sebagai modal sosial. Warga perempuan dapat menggerakan individu dan komunitas masyarakat untuk berperan serta dan aktif dalam pengelolaan lingkungan (Blocker dan Eckberg, 1997). Warga perempuan dapat menjadi agen perubahan dalam pengelolaan lingkungan di perkotaan, bahkan menjadi bagian dari penyelesaian konflik lingkungan di perkotaan (Asteria, 2013).

Selain itu, pengelolaan sampah masih belum menjalani proses pengelolaan sampah dengan menggunakan metode reduce, reuse, recycle dan replant (4R) dari sumber, pada kajian sebelumnya masih menggunakan prinsip reduce, reuse dan recycle (3R) saja. Dengan demikian pada pengembangan bank sampah dengan swadaya masyarakat di Kampung Karangresik, Kota Tasikmalaya, didasari oleh beberapa permasalahan lingkungan di komunitas. Penerapan pengelolaan sampah masih dari sumber (rumah tangga/masyarakat) yang langsung dibuang ke tempat sampah dan selanjutnya diambil oleh petugas baik dari partisipasi masyarakat/RW atau DKP 
diangkut ke Tempat Pembuangan Sementara (TPS) dan dari TPS diangkut oleh Petugas DKP ke tempat pembuangan akhir (TPA).

Secara sosial, sebagian besar masyarakat di Kampung Karangresik, Kota Tasikmalaya belum peduli terhadap pengelolaan sampah dan walaupun ada pengelolaan sampah masih bersifat individual dan belum terorganisir secara terpadu, sehingga intensitas kebersamaan dalam komunitas masih sangat rendah. Kemudian secara ekonomi, saat ini belum ada nilai ekonomis terhadap pengelolaan sampah, selain masyarakat belum paham terhadap pengelolaan sampah yang mempunyai nilai ekonomis dengan 4R dan sebagian besar kesadaran terhadap pengelolaan sampah masih rendah dikarenakan masyarakat masih menganggap bahwa sampah merupakan sisa dari sebuah proses yang tidak diinginkan dan tidak mempunyai nilai ekonomis. Berkaitan dengan masalah timbulan sampah, masih adanya masyarakat yang membuang sampah bukan pada tempatnya terutama di sungai/saluran dan dibakar yang menyebabkan lingkungan menjadi kotor, timbulnya berbagai macam penyakit, pencemaran lingkungan dan kerusakan ekosistem.

Untuk alternatif solusi dalam mengatasi masalah sampah di perkotaan, pengembangan bank sampah merupakan kegiatan bersifat social engineering (Ridley-Duff dan Bull, 2011) yang mengajarkan masyarakat untuk memilah sampah serta menumbuhkan kesadaran masyarakat dalam pengolahan sampah. Pembentukan bank sampah harus diintegrasikan dengan gerakan program $4 \mathrm{R}$ sehingga warga akan memperoleh manfaat langsung, tidak hanya secara ekonomi, juga terwujudnya kesehatan lingkungan, dengan kondisi komunitas yang bersih, hijau, nyaman, dan sehat. Selain itu, bank sampah memberikan manfaat secara sosial dengan memperkuat kohesi sosial bagi keberadaan komunitas perempuan yang selama ini termarjinalisasi dalam konstruksi sosial budaya. Manfaat lainnya secara ekonomis memberi dampak berupa tambahan penghasilan, dan manfaat untuk lingkungan dapat mengurangi timbulan sampah di perkotaan.

Tujuan penulisan adalah memberikan alternatif strategi dalam pengelolaan sampah dengan edukasi warga melalui pembentukan bank sampah yang diintegrasikan dengan prinsip 4R, dapat membangun kepedulian masyarakat agar dapat 'berkawan' dengan sampah, serta untuk mendapatkan manfaat secara sosial, ekonomi, dan lingkungan dari pemilahan sampah yang ditabung ke bank sampah. Hal ini sebagaimana temuan Mulasari dkk. (2014) mengenai pentingnya penerapan kebijakan pengelolaan sampah domestik

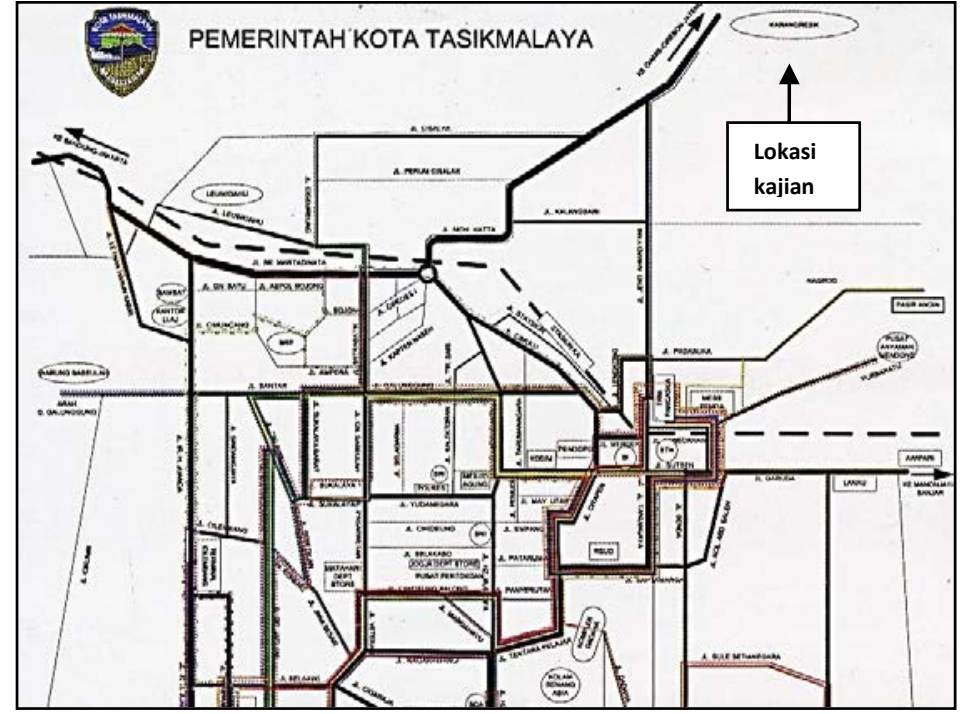

Gambar 1. Lokasi program pengembangan bank sampah Bank Sampah Pucuk Resik (BSPR) di Kampung Karangresik, Kota Tasikmalaya.

memerlukan kemandirian warga dalam pengelolaannya.

\section{METODE}

\section{Waktu dan Lokasi}

Program edukasi pengembangan bank sampah yang dilaksanakan di Kampung Karangresik, Kecamatan Cipedes, Kota Tasikmalaya, sejak awal tahun 2014 hingga bulan Mei 2015. Pemilihan lokasi di Kampung Karangresik, Kota Tasikmalaya dikarenakan merupakan wilayah yang dekat dengan Sungai Citanduy dengan banyaknya sampah yang dibuang ke sungai sehingga terjadi banjir. Selain itu, kesadaran dan partisipasi masyarakat setempat menerapkan 4R dalam mengolah sampah masih rendah. Berdasarkan informasi pihak TPA setempat, diketahui timbulan sampah mencapai rata-rata 1627 $\mathrm{m}^{3} /$ hari, banyaknya tumpukan sampah di pinggir jalan dan masih banyak warga setempat yang membuang sampah ke sungai.

\section{Prosedur}

Kegiatan ini merupakan kaji terap dan edukasi masyarakat melalui pengembangan bank sampah yang dilakukan dengan menggunakan metode partisipasi-emansipatoris. Kegiatan edukasi kepada masyarakat diberikan melalui pelatihan yang diberikan berupa pelatihan wirausaha untuk mengelola bank sampah dan pelatihan daur ulang sampah menjadi produk daur ulang, baik pupuk kompos dan barang kerajinan dari sampah daur ulang. Bank sampah yang dikembangkan di Kampung Karangresik ini diberi nama Bank Sampah Pucuk Resik (BSPR). Fokus pembinaan kepada warga perempuan yang menjadi pengurus PKK setempat, sebagai role model bagi warga perempuan lainnya, dengan penyebaran sosialisasi berlangsung 
secara getok tular, informasi disebarkan saat kegiatan rutin PKK, pengajian, dan pertemuan warga.

Secara garis besar penerapan metode dilakukan sebagaimana berikut ini, yaitu dengan melakukan pendekatan kepada warga dan stakeholders. Dengan warga dilakukan dengan interaksi dan komunikasi tatap muka melalui dialog dan pertemuan-pertemuan dengan warga di komunitas, tidak hanya pada saat kegiatan sosialisasi dan edukasi dilakukan. Dengan stakeholders dilakukan dengan mengupayakan adanya dialog dan kerja sama, khususnya pemerintah daerah setempat (di level kelurahan, kecamatan, Dinas Kebersihan dan Pertamanan Kota), pengumpul/pengepul, pengangkut/pemulung sampah, dan pengembangan kerja sama yang bersifat multi-stakeholder dengan pihak LSM maupun pihak swasta di tingkat lokal maupun regional.

Untuk pelaksanaan pengembangan bank sampah, dilakukan pembinaan kepada 15 pengurus PKK mengenai pengetahuan manajemen keuangan sederhana agar mampu melakukan pencatatan sampah yang disetorkan warga dan penyerahan buku tabungan pada warga. Sampah yang disetorkan berasal dari sampah domestik warga Kampung Karangresik yang menjadi nasabah, yaitu warga RW 10 dan RW 11 berjumlah 254 nasabah. Penyerahan dan pengumpulan sampah dilakukan pada setiap hari Rabu dimulai sejak pukul 8 pagi hingga siang hari. Sementara untuk penimbangan sampah dilakukan oleh para para pemuda yang masih menganggur sehingga melibatkan lapisan masyarakat di komunitas.

\section{HASIL DAN PEMBAHASAN}

Bank sampah mengajarkan masyarakat untuk memilah sampah, menumbuhkan kesadaran masyarakat mengolah sampah secara bijak agar dapat mengurangi sampah yang diangkut ke TPA. Selain itu warga yang menyerahkan sampah akan memperoleh tambahan penghasilan untuk kemandirian ekonomi warga dapat digunakan untuk usaha simpan pinjam seperti koperasi, dengan bunga rendah agar keuangan bank sampah dapat diputar dan dikembangkan, juga terwujudnya kesehatan lingkungan. Pembinaan warga perempuan telah menunjukkan kemampuan warga perempuan dalam menggerakkan komunitasnya untuk berperan aktif mengelola sampah di lingkungannya sekaligus melakukan kontrol sosial di komunitasnya.

Pembentukan bank sampah yang diintegrasikan dengan edukasi mengenai prinsip $4 \mathrm{R}$ menjadi pengetahuan dasar bagi warga untuk mengelola sampah sejak dari sumbernya, yaitu sampah rumah tangga. Pemberdayaan warga untuk membentuk pengetahuan dan keterampilan warga sehingga mampu memilah sampah organik dan non organik. Manfaat dari kemampuan warga mengelola sampah dengan menerapkan prinsip 4R dan menabung ke bank sampah telah memberikan manfaat langsung, tidak hanya secara ekonomi, juga terwujudnya kesehatan lingkungan, dengan kondisi komunitas yang bersih, hijau, nyaman, dan sehat. Perubahan yang terjadi di komunitas lokasi pengembangan bank sampah dapat dilihat pada Tabel 1 .

Dalam pelaksanaan edukasi warga dengan pengembangan bank sampah, harus terus dilakukan koordinasi secara intensif dengan para pengurus PKK pada setiap kegiatan yang akan dilakukan agar pemberdayaan warga menjadi lebih maksimal. Selain itu berkaitan Tabel 1, berdasarkan pengamatan di lokasi binaan dengan masih banyaknya tumpukan sampah pada pojok gang dan timbunan sampah di sungai, menunjukan bahwa kondisi minimnya pengetahuan warga mengenai lingkungan dan cara pengelolaan sampah. Berdasarkan data BPS 2010-2013, kondisi demografi warga Kota Tasikmala sebanyak 47,14\% warga hanya mencapai pendidikan SD/MI, dan $16,61 \%$ mencapai pendidikan tingkat SMP dan $21,13 \%$ mencapai pendidikan tingkat SMA. Untuk jenis pekerjaan warga sebanyak 49,36\% menjadi buruh dan sebanyak 2,77\% bekerja tanpa menerima upah (Anonim, 2013). Maka perubahan perilaku warga memerlukan cara pendekatan secara perlahan dalam mengubah kebiasaan dan tentunya tidak mudah dilakukan dalam waktu singkat. Pendekatan kepada warga terus dilakukan melalui ajaran Islam agar menjaga kebersihan dan nilai sosial-budaya pada komunitas binaan.

Selain upaya memaksimalkan kemampuan dan keterampilan warga, upaya memantau perkembangan harga sampah di pasaran juga harus terus dilakukan. Hal ini sangat mendasar untuk keberlanjutan bank sampah, sehingga koordinasi dan kerja sama dengan para pengepul baik yang termasuk kategori pengepul besar dan kecil di sekitar Kampung Karangresik harus terus dibina. Dengan demikian penting dilakukan pembinaan kemitraan dengan pabrik pengolahan sampah plastik yang terletak dekat Kampung Karangresik. Sampah plastik dari bank sampah, salah satunya jenis plastik kresek hitam yang tidak laku dijual akan diolah di pabrik. Pabrik menjadi mitra konsumen utama sampah plastik dari bank sampah untuk jenis sampah yang tidak diterima oleh pengepul karena nilai jual yang rendah. Adapun jenis sampah yang ditabung warga ke bank sampah sebagaimana Tabel 2.

Sampah yang disetorkan sebagaimana pada Tabel 2 berasal dari sampah domestik warga Kampung Karangresik dari warga RW 10 dan RW 11 dengan jumlah 254 nasabah. Pemilahan sampah 
Tabel 1. Perubahan kondisi sebelum dan setelah pengembangan edukasi bank sampah.

\begin{tabular}{lllll}
\hline No & \multicolumn{3}{c}{ Kondisi sebelum } & \multicolumn{2}{c}{ Kegiatan } \\
\hline 1. & Secara teknis: kendaraan angkut & Pemetaan masalah dengan melakukan \\
& sampah banyak yang rusak, belum & pertemuan dan dialog dengan warga \\
menerapkan prinsip 4R dan belum & perempuan mengenai dampak masalah \\
memiliki teknologi pengolahan sampah & $\begin{array}{l}\text { sampah bagi lingkungan dan kesehatan } \\
\text { warga }\end{array}$
\end{tabular}

2. Secara sosial: partisipasi warga rendah

3. Secara ekonomi: sampah dianggap tidak memiliki nilai ekonomi dan manfaat

4. Timbulan sampah: mencapai 1627 meter kubik per hari

5. Secara sistem: masih kumpul-angkutbuang dan keterbatasan lahan untuk pewadahan sampah

6. Kondisi lingkungan yang masih mengalami masalah banjir akibat gorong-gorong tersumbat sampah
Pertemuan sosialisasi kesadaran lingkungan kepada warga perempuan, sekaligus dilakukan arahan dan dialog untuk memberikan pengetahuan mengenai kesadaran lingkungan dan pembagian bibit tanaman (yang memanfaatkan sampah plastik sebagai kantong untuk media pembibitan atau polyback)

- Pendataan harga sampah plastik di pasaran dengan melakukan observasi dan bekerja sama dengan para pengepul. Telah dilakukan kerja sama dengan 10 pengepul, yaitu 3 pengepul besar dan 7 pengepul kecil

- Kerja sama dengan pemilik pabrik pengolahan kantong kresek bekas yang tidak laku atau tidak diambil oleh pemulung dan bandar barang rongsokan.

Publikasi kegiatan pada media surat kabar lokal di Tasikmalaya, yaitu surat kabar Kabar Priangan*

Melalui dialog dan pelatihan, warga telah dapat memilah sampah dan mampu membuat produk daur ulang

Upaya mengajak warga peduli membersihkan gorong-gorong dan melakukan pemilahan sampah plastik lalu memotivasi warga untuk menabung ke bank sampah

\begin{abstract}
Warga memiliki pengetahuan mengenai dampak masalah sampah, sehingga mulai terjadi perubahan kebiasaan warga perempuan, yang mulai aktif melakukan pemilahan sampah rumah tangga, dengan penerapan prinsip 4R
\end{abstract}

Semakin banyak warga mulai menyetorkan sampah ke bank sampah dan berkontribusi aktif, dengan partisipasi warga perempuan anggota PKK dalam kepengurusan bank sampah.

Mulai tampak perubahan kondisi lingkungan secara fisik dengan penurunan jumlah sampah yang dibuang ke sungai maupun yang dibuang sembanrangan, dan lingkungan tampak lebih bersih.

Dukungan pihak RT, RW, dan kelurahan setempat dalam aktivitas dialog dengan warga dan pelatihan yang diberikan

Warga semakin banyak menabung ke bank sampah dan mulai membuat beberapa produk kerajinan: tas/map dan sandal

Kondisi lingkungan telah lebih bersih dan sehat*

Sumber : Hasil pengamatan.

Tabel 2. Jenis sampah non organik yang disetorkan di Bank Sampah Pucuk Resik (BSPR) di Kampung Karangresik, Tasikmalaya.

\begin{tabular}{|c|c|c|c|c|}
\hline No & Jenis sampah & $\begin{array}{c}\text { Per } \\
\text { minggu/kg }\end{array}$ & $\begin{array}{c}\text { Per } \\
\text { bulan } / \mathrm{kg}\end{array}$ & $\begin{array}{c}\text { Rata-rata/ } \\
\text { nasabah/bulan }\end{array}$ \\
\hline 1. & $\begin{array}{l}\text { Kantong keresek (keresek hitam, putih, bening, bungkus } \\
\text { mie, bungkus minyak, bungkus kopi dan lainnya) }\end{array}$ & $36 \mathrm{~kg}$ & $144 \mathrm{~kg}$ & $0,72 \mathrm{~kg}$ \\
\hline 2. & $\begin{array}{l}\text { Jenis plastik ember (ember, ember hitam, mainan anak, aqua } \\
\text { gelas, ale-ale, teh gelas, paralon, aqua botol dan lainnya) }\end{array}$ & $57 \mathrm{~kg}$ & $288 \mathrm{~kg}$ & $1,45 \mathrm{~kg}$ \\
\hline 3. & $\begin{array}{l}\text { Kertas (dus, kertas putih, buku, bungkus rokok, karton, } \\
\text { kertas koran, kertas buram dan lainnya) }\end{array}$ & $17,5 \mathrm{~kg}$ & 70 kg & $0,35 \mathrm{~kg}$ \\
\hline 4. & $\begin{array}{l}\text { Logam (besi, almunium, katel bekas, seng, payung bekas, } \\
\text { kaleng dan lainnya) }\end{array}$ & $22 \mathrm{~kg}$ & $88 \mathrm{~kg}$ & $0,44 \mathrm{~kg}$ \\
\hline 5. & Nilex ( jepit sandal bekas, selang, sepatu bekas dan lainnya) & $10 \mathrm{~kg}$ & $40 \mathrm{~kg}$ & $0,20 \mathrm{~kg}$ \\
\hline 6. & Beling (Botol kratingdeng, minyak wangi, obat dan lainnya) & $32 \mathrm{~kg}$ & $128 \mathrm{~kg}$ & $0,64 \mathrm{~kg}$ \\
\hline 7. & $\begin{array}{l}\text { Botol (botol bir, sirup ABC, botol kecap, botol marjan, botol } \\
\text { saus dan lainnya) }\end{array}$ & 53 biji & 212 biji & 1,07 biji \\
\hline
\end{tabular}

Sumber : Hasil pengamatan.

telah dilakukan oleh warga sebelum mengantarkannya ke bank sampah. Pengetahuan warga mengenai jenis sampah dan cara pengelolaannya, khususnya sampah plastik merupakan hal penting dalam pengembangan bank sampah dan pengembangan produksi produk daur 
ulang. Edukasi pada warga dapat mengubah kebiasaan warga dalam mengelola sampah. Kehadiran bank sampah menjadi salah satu alternatif dalam mengatasi masalah sampah di perkotaan yang saat ini masih mengalami kompleksitas masalah dalam penerapannya, dikarenakan belum terintegrasi dan masih bersifat lokal.

Pengembangan bank sampah akan lebih terintegrasi dengan adanya dukungan dari pemda setempat dan pihak pengusaha lokal menjadi sangat penting. Pada dasarnya intervensi pihak pemerintah daerah setempat diperlukan dalam mendukung kelancaran kegiatan serta peran pihak perusahaan/pengusaha lokal diperlukan untuk meningkatkan nilai ekonomis dari pengolahan sampah di komunitas

\section{KESIMPULAN}

Kehadiran bank sampah telah mendorong adanya capacity building bagi warga dengan mengupayakan terbentuknya kemandirian dan keswadayaan warga melalui terbentuknya kesadaran, pengetahuan, dan kemampuan yang mendorong partisipasi mengelola lingkungan di komunitasnya. Khususnya bagi warga perempuan, pengetahuan dan keterampilan mengelola sampah telah menstimulasi kreativitas dan inovasi kerajinan daur ulang sampah.

\section{UCAPAN TERIMAKASIH}

Penulis mengucapkan terima kasih kepada pihak Direktorat Riset dan Pengabdian Masyarakat Universitas Indonesia (DRPM UI) atas kontrak Nomor 4796/UN2.R12/HKP 05.00 Perjanjian/2014, yang telah mendukung kegiatan pengabdian masyarakat di Tasikmalaya yang menjadi kajian dalam tulisan ini.

\section{DAFTAR PUSTAKA}

Anonim, 2012. Profil Bank Sampah Indonesia 2012. Kementerian Lingkungan Hidup, Jakarta.

Anonim, 2013. Statistik Kota Tasikmala. Badan Pusat Statistik, Tasikmalaya.

Asteria, D., 2013. Model Komunikasi Lingkungan Berperspektif Gender dalam Menyelesaikan Konflik Lingkungan di Perkotaan: Peran Aktivis Perempuan dalam Pengelolaan Konflik Lingkungan Secara Berkelanjutan. PUPT BOPTN 2013. Universitas Indonesia, Depok.
Akhtar, H., dan Soetjipto, H.P., 2014. Peran Sikap dalam Memediasi Pengaruh Pengetahuan Terhadap Perilaku Minimisasi Sampah Pada Masyarakat Terban, Yogyakarta. Jurnal Manusia dan Lingkungan, 21(3):386-392.

Blocker, T.J., dan Eckberg, D.L., 1997. Gender and Environmentalism: Result from the 1993 General Social Survey. Social Science Quarterly, 78(4):841-858.

Jumar, Fitriyah, N., dan Kalalinggie, R., 2014. Strategi Pengelolaan Sampah Rumah Tangga di Kelurahan Lok Bahu Kecamatan Sungai Kunjang Kota Samarinda. Journal Administrative Reform, 2(1):771-782

Kristina, H., 2014. Model Konseptual Untuk Mengukur Adaptabilitas Bank Sampah di Indonesia. Jurnal Teknik Industri, 9(1):19-28.

Mulasari, S.A., Husodo, A.H., dan Muhadjir, N., 2014. Kebijakan pemerintah Dalam Pengelolaan Sampah Domestik. Jurnal Kesehatan Masyarakat Nasional, 8(8):404410.

Purba, H.D., Meidiana, C., dan Adrianto, D.W., 2014. Waste Management Scenario through Community Based Waste Bank: A Case Study of Kepanjen District, Malang Regency, Indonesia. International Journal of Environmental Science and Development, 5(2):212-216

Ridley-Duff, R.J., dan Bull, M., 2011. Understanding Social Enterprise: Theory and Practice, Sage Publication, London.

Riswan, Sunoko, H.R., dan Hadiyarto, A., 2011. Pengelolaan Sampah Rumah Tangga di Kecamatan Daha Selatan. Jurnal Ilmu Lingkungan, 9(1):31-38.

Singhirunnusorn, W., Donlakorn, K., dan Kaewhanin, W., 2012. Household Recycling Behaviours and Attitudes toward Waste Bank Project: Mahasarakham Municipality. Journal of Asia Behavioural Studies, 2(6):35-47.

Trina, E., Tallei, T.E., Iskandar, J., Runtuwene, S., dan Filho, W.L., 2013. Local Communitybased Initiatives of Waste Management Activities on Bunaken Island in North Sulawesi, Indonesia. Research Journal of Environmental and Earth Sciences, 5(12):737-743.

Winarso, H., dan Larasati, A., 2011. Dari Sampah Menjadi Upah: Inovasi Pengolahan Sampah di Tingkat Akar Rumput Kasus Program Bank Sampah "Sendu" di Kelurahan Pasar Minggu Jakarta Selatan. Jurnal Manusia dan Lingkungan, 18(1):43-59. 